\title{
Fatigue behavior of endodontically treated premolars restored with different fiber-reinforced designs
}

\author{
Márk Fráter ${ }^{a}$, Tekla Sáry ${ }^{a}$, Blanka Jókai ${ }^{a}$, Gábor Braunitzer $^{b}$, \\ Eija Säilynoja ${ }^{c, d}$, Pekka K. Vallittu ${ }^{c, e}$, Lippo Lassila ${ }^{c}$, Sufyan Garoushi ${ }^{c, *}$ \\ a Department of Operative and Esthetic Dentistry, Faculty of Dentistry, University of Szeged, Szeged, Hungary \\ b dicomLAB Dental Ltd., Szeged, Hungary \\ c Department of Biomaterials Science and Turku Clinical Biomaterials Center -TCBC, Institute of Dentistry, \\ University of Turku, Turku, Finland \\ $\mathrm{d}$ Research Development and Production Department, Stick Tech Ltd - Member of GC Group, Turku, Finland \\ e City of Turku, Welfare Division, Turku, Finland
}

\section{A R T I C L E I N F O}

\section{Article history:}

Available online xxx

Keywords:

Premolar teeth

Endodontically treated teeth

Short fiber-reinforced composite

Fatigue survival

Bioblock technique

\begin{abstract}
A B S T R A C T
Objectives. The aim was to investigate the fatigue survival and marginal-gap inside the rootcanal of endodontically treated (ET) premolars reinforced by various fiber-reinforced postcore composites (FRCs). Moreover, composite-curing at different depths in the canal was evaluated.

Methods. 170 intact upper-premolars were collected and randomly divided into ten groups (n =15). One group served as control (intact-teeth). After endodontic procedure standard MO cavities were prepared and restored with different post-core fiber-reinforced materials and designs. Three-group (A1-A3) were restored with either packable and flowable short fiberreinforced composite (SFRC) core or conventional composite-core. Two-group (B1-B2) were restored with SFRCs as short post $(3 \mathrm{~mm}$ ) and core. Four-group (C1-C4) were restored with SFRCs as post $(6 \mathrm{~mm})$ and core with or without unidirectional FRC posts (individually-made or conventional). After completing the restorations, teeth from Group C1-C4 ( $n=5 /$ group) were sectioned and stained. Specimens were viewed under a stereo-microscope and the percentage of microgaps within the root-canal was calculated. Fatigue-survival was measured using a cyclic-loading machine in the rest of the specimens.

Results. Application of flowable SFRC as luting-core material with individually-made FRC post (Group C3) did not differ from intact-teeth regarding fatigue-survival $(p>0.05)$. The rest of the groups produced significantly lower survival $(p<0.05)$ compared to intact-teeth. Post/core restorations made from packable SFRC (Group C1) had a lower microgap (19.1\%) at the examined interphase in the root-canal than other groups.

Significance. The restoration of ET premolars with the use of individually-made FRC post and SFRC as luting-core material showed promising achievement regarding fatigue-resistance and survival.
\end{abstract}

(c) 2020 The Academy of Dental Materials. Published by Elsevier Inc. All rights reserved.

* Corresponding author at: Department of Biomaterials Science, Institute of Dentistry and TCBC, University of Turku, Turku, Finland.

E-mail address: sufgar@utu.fi (S. Garoushi).

https://doi.org/10.1016/j.dental.2020.11.026

0109-5641/@ 2020 The Academy of Dental Materials. Published by Elsevier Inc. All rights reserved. 


\section{Introduction}

Caries, trauma and cavity preparation may cause too much loss of coronal tooth structure, which is a major challenge to the clinicians during the restoration of root canal treated (RCT) teeth [1]. As a result of lost structural integrity, RCT teeth are weak and reveal limited resistance to fracture [2,3]. This is mostly critical in the instance of RCT premolars, as several investigations reporting a high fracture incidence for these teeth, especially in the upper arch [4-6]. Upper premolars are subjected to a combination of compressive and shearing forces, which drives them particularly prone to fracture [7]. The marginal ridges loss leads this even more noticeable. Reeh et al., clearly showed that the loss of marginal ridge integrity resulted in considerable loss of stiffness [3,8]. While a standardized MOD (mesio-occlusal-distal) cavity preparation in upper premolars was proved to lead in mean loss of $63 \%$ in relative cuspal stiffness [9], the loss of only one marginal ridge resulted in a loss of only $46 \%$ in elative cuspal stiffness [10]. Therefore, intracoronal reinforcement of RCT premolars is essential to defend them against fracture $[7,11]$. Since the 1990s, fiber-reinforced composite (FRC) posts have been used with increasing frequency to restore RCT teeth with excessive loss of coronal tooth structure [12]. The sole aim of this approach is to inhance the retention of the core build-up material. Many researchers reported that using a post into RCT premolars considerably improved their fracture resistance [13-16], though, other researchers just managed to confirm the beneficial effect of placing a post on the fracture mode of such premolar teeth [17-19]. This was also approved by Trope et al. [20], and Zicari et al. [21], who assumed that placement of FRC post does not really enhance or reinforce the given tooth. This could be caused by multiple reasons, namely the possible weakening of the root during the post space preparation [21-23], the inaccurate fit of the post due to the irregular geometry and cross section of the root canal [24,25], or the inability of the post material to adequately bond to the luting or core build-up material $[26,27]$.

Applying short fiber-reinforced composites (SFRC) inside the root canal has been suggested by many authors [28-30]. In the Bioblock technique, both the coronal cavity and the root canal are filled by packable SFRC in $4-5 \mathrm{~mm}$ thick horizontal increments [30,31]. From our previous research, premolar teeth restored with the Bioblock technique showed significantly higher fracture resistance compared to the ones restored with an FRC post [31]. In 2019, the flowable version of SFRC was released with the promise of easy versatility or adaptability in limited spaces (e.g. root canals). In our latest study, apexified anterior teeth restored with the Bioblock technique using the flowable SFRC did not differ significantly from the intact teeth (control group) in terms of survival, whereas the rest of the tested groups had significantly lower survival rates compared to the control group [31].

The question arises whether one may use just any version of SFRC to restore RCT premolar teeth with mesio-occlusal (MO) cavities or long fibers (in the form of FRC posts) are preferable. The purpose of this laboratory investigation was to evaluate the fatigue resistance and failure mode of RCT premolar with MO cavities restored by different direct techniques with FRC materials. Furthermore, adaptation within the root canal and curing quality at different depths were studies for each technique.

\section{Materials and methods}

The study was approved by the Ethics Committee of the University of Szeged, and was designed in accordance with the declaration of Helsinki.

One hundred seventy upper premolar teeth, extracted for periodontal or orthodontic causes were used for this research. The newly extracted premolars were directly inserted in $5.25 \%$ $\mathrm{NaOCl}$ for $5 \mathrm{~min}$ and stored in $0.9 \%$ saline solution at room temperature. Teeth were used during 8 weeks after extraction. At time of specimen preparation hand scaler was used to remove the soft tissue covering the root surface. The teeth selection criteria were absence of caries, cracks, previous endodontic treatments, posts or crowns, root resorptions and obvious accessory canals. Radiographs from different directions for all teeth were taken and examined to evaluate the number of existing canals and the root integrity. In order to standardize the test set-up, all premolars used in this reasearch had one root canal with a curvature of less than $5^{\circ}$, evaluated by Schneider's technique [32], and premolars with a root length of $15 \pm 1 \mathrm{~mm}$ and equal mesiodistal and bucco-lingual dimensions $( \pm 10 \%)$ were selected. $90 \%$ of the premolars ranged $9-10 \mathrm{~mm}$ in size, assessed at the widest bucco-lingual dimension, and the rest measured teeth were $6.5-8 \mathrm{~mm}$. From the mesio-distal dimension, $90 \%$ of the teeth ranged $7-7.5 \mathrm{~mm}$, and the rest were $6.5-8 \mathrm{~mm}$.

Teeth were randomly divided over ten test groups, where four groups (Group C1-C4) contained of 20 specimens each, and the rest of the groups only containing 15 specimen. One group containing 15 teeth was left intact to serve as control. Class II. MO cavity preparation and later on root canal treatment was conducted by the same trained dental practitioner in the rest of the groups (Group A1-A3,B1-B2 and C1-C4).

\subsection{Specimen preparation}

A standardized MO cavity was prepared on teeth using a round end paralel diamond bur (883H.146.016 F G - Brasseler USA Dental, Savannah, GA) with water coolant so that the buccopalatal width of the occlusal isthmus was one third, and the proximal box width was two thirds of the buccopalatal width of the crown. The gingival floor was prepared $1 \mathrm{~mm}$ above the cemento-enamel junction (CEJ). All internal angles were rounded and the cavosurface margins were at $90^{\circ}$. After finalizing the MO cavity preparation, access cavity preparation was perfromed with a round-end diamond bur (850-014 M SSWhite, Lakewood, NJ, USA) with water cooling and root canal treatment was made in the prepared teeth. The working length was created with the direct method by subtracting 1 $\mathrm{mm}$ from the real root length defined by introducing a number $10 \mathrm{~K}$-file (Maillefer-Dentsply, Ballaigues, Switzerland) until it was visible through the apical foramen. The root canals were prepared using rotary ProTaper Universal files (Dentsply, Maillefer, Ballaigues, Switzerland). The ProTaper sequence (S1, S2, F1, F2) was used for the preparation at the working 
length. Irrigation was done after every instrument with $2 \mathrm{ml}$ of $2.5 \% \mathrm{NaOCl}$ solution and the canal space was saturated with irrigant during the instrumentation phase. After root canal cleaning and shaping, the roots were dried using $96 \%$ alcohol and paper points. Root canal obturation was made by matched single-cone obturation with a master cone (F2 guttapercha, Maillefer-Dentsply, Ballaigues, Switzerland) and sealer (AH plus; Dentsply De Trey GmbH, Konstanz, Germany). The guttapercha was cut back to the level of the orifice and the access cavity was temporarily filled with Fuji Triage Pink (GC Europe, Leuven, Belgium). Fuji Triage Pink was applied to the apical part of the root in order to prevent leakage through the apex. The teeth were stored wet in an incubator (mco-18aic, Sanyo, Japan) for one week (at $37{ }^{\circ} \mathrm{C}, 100 \%$ relative humidity). After this the temporary material was removed and the MO cavity, including the access cavity was refreshened with a diamond bur.

In Group A1-A3 the root canal was no longer invaded by any preparation and teeth were restored with MO filling without any radicular reinforcement. In Group B1-B2 a very shallow post space preparation was carried out by a 1.2 GC Fiber Post drill to a depth of $3 \mathrm{~mm}$ apical from the root canal orifice. In Group C1-C4 post space preparation was carried out by a 1.2 GC Fiber Post drill to a depth of $6 \mathrm{~mm}$ apical from the root canal orifice. After cutting back the gutta-percha, the root canal was washed with chlorhexidine and dried with paper points.

All specimen had the same adhesive treatment. Tofflemire (1101C 0.035, Hawe-Neos, Italy) matrix band was applied prior to the adhesive treatment of the cavity and the root canal, the enamel was selectively acid-etched with $37 \%$ phosphoric acid for $15 \mathrm{~s}$ and washed with water. The coronal cavity and the root canal were rinsed with $2 \mathrm{ml}$ of water and dried with paper points and air. A dual-cure one-step self-etch adhesive system (G-Premio Bond and DCA, GC Europe, Leuven, Belgium) was used for bonding procedure according to the manufacturer's instructions using a microbrush-X disposable applicator (Pentron Clinical Technologies, LLC, USA). Extra adhesive was eliminated by suction drying (Evacuation Tip - Starryshine, Anaheim, CA, USA) within $0.5 \mathrm{~cm}$ from the occlusal cavity (without contact). The excess adhesive resin at the bottom of the canal was eliminated using a paper point. The adhesive was light-cured for $60 \mathrm{~s}$ using an Optilux 501 quartz-tungstenhalogen light-curing unit (Kerr Corp., Orange, CA, USA). The light-curing tip was always located in close contact (1-2 $\mathrm{mm}$ ) with the tooth surface. The average power density of the light source, measured with a digital radiometer (Jetlite light tester; J. Morita USA Inc. Irvine, CA, USA) before the bonding procedure, was $840 \pm 26.8 \mathrm{~mW} / \mathrm{cm}^{2}$. After light-curing the adhesive, the missing interproximal walls were build-up with conventional composite (G-aenial Posterior PJ-E, GC Europe, Leuven, Belgium) using the centripetal technique, thus transforming the MO cavity into a class I. cavity. This interproximal wall was light cured for $40 \mathrm{~s}$.

Nine different techniques were used to restore the specimens in Group A1-C4. (Fig. 1):

Group A1: The cavities were restored with packable SFRC (everX Posterior, GC Europe, Leuven, Belgium) applied in a bulk-fill technique. The material was placed in single increment according to the anatomy of the dentine, leaving 1.5-2 $\mathrm{mm}$ occlusally for the final composite layers as prescribed by the manufacturer. The SFRC increment was light cured from the occlusal surface for $40 \mathrm{~s}$. The last occlusal layer was conventional composite material (G-aenial Posterior PJ-E) covering the SFRC.

Group A2: The cavities were restored with flowable SFRC (everX Flow, GC Europe, Leuven, Belgium) applied in a bulkfill technique. The material was placed in single increment according to the anatomy of the dentine, leaving $1.5-2 \mathrm{~mm}$ occlusally for the final composite layers as prescribed by the manufacturer. The SFRC increment was light cured from the occlusal surface for $40 \mathrm{~s}$. The last occlusal layer was conventional composite material covering the SFRC.

Group A3: The cavities were restored with conventional composite material (G-aenial Posterior) applied with an oblique incremental technique. The material was placed in consecutive $2 \mathrm{~mm}$ thick increments. Each increment was light cured from the occlusal surface for $40 \mathrm{~s}$.

Group B1: The cavities including the $3 \mathrm{~mm}$ deep post space were restored with packable SFRC applied in a horizontal layering technique. The material was placed in 2 increments (approx. $4 \mathrm{~mm}$ thick each) according to the anatomy of the dentine. The light curing of the layers and covering with a final occlusal layer of composite material was performed as in Group A1.

Group B2: The cavities including the $3 \mathrm{~mm}$ deep post space were restored with flowable SFRC the same way as described in Group B1.

Group C1: The cavities and the $6 \mathrm{~mm}$ deep post space were reconstructed with the Bioblock technique described by Fráter et al., [30] building a direct layered post and core from packable SFRC. An approx. $4 \mathrm{~mm}$ thick increment of using a microbrush$\mathrm{X}$ disposable applicator (Pentron Clinical Technologies, LLC, USA). A light transmitting FRC post (1.2 mm GC Fiber post, GC Europe, Leuven, Belgium) was inserted into the post space to aid the transmission of the light to the apically positioned layers. The 'light transmitting' post was withdrawn with 0.5-1 $\mathrm{mm}$ from the surface of the uncured SFRC layer not to have direct contact with it. This apical layer was light cured through the fiber post for $80 \mathrm{~s}$. The rest of the cavity was restored as described in Group A1.

Group C2: The cavities and the $6 \mathrm{~mm}$ deep post space were restored with the Bioblock technique with the use of flowable SFRC. The coronal portion of the cavity was restored as described in Group A2

Group C3: The teeth received an individually-made unidirectional FRC post (everStick Post, GC Europe, Leuven, Belgium). Before the adhesive treatment, the posts of $1.2 \mathrm{~mm}$ diameter was tried in and cut to a length $2 \mathrm{~mm}$ below the level of the occlusal cavity margins with a sterile scrissors. Luting of the posts and the core build-up was performed with flowable SFRC. Flowable SFRC was applied in an approx. $4 \mathrm{~mm}$ thick layer into the post space. After insertion of the post, light curing was performed for $60 \mathrm{~s}$. The coronal portion of the cavity was restored as described in Group A2.

Group C4: The teeth received a conventional unidirectional FRC post (GC Fiber post, GC Europe, Leuven, Belgium). Before the adhesive treatment, the conventional translucent FRC posts of $1.2 \mathrm{~mm}$ diameter was tried in and cut to a length $2 \mathrm{~mm}$ below the level of the occlusal cavity margins with a watercooled diamond disc (Isomet 2000; Buehler Ltd., Lake Bluff, IL, 


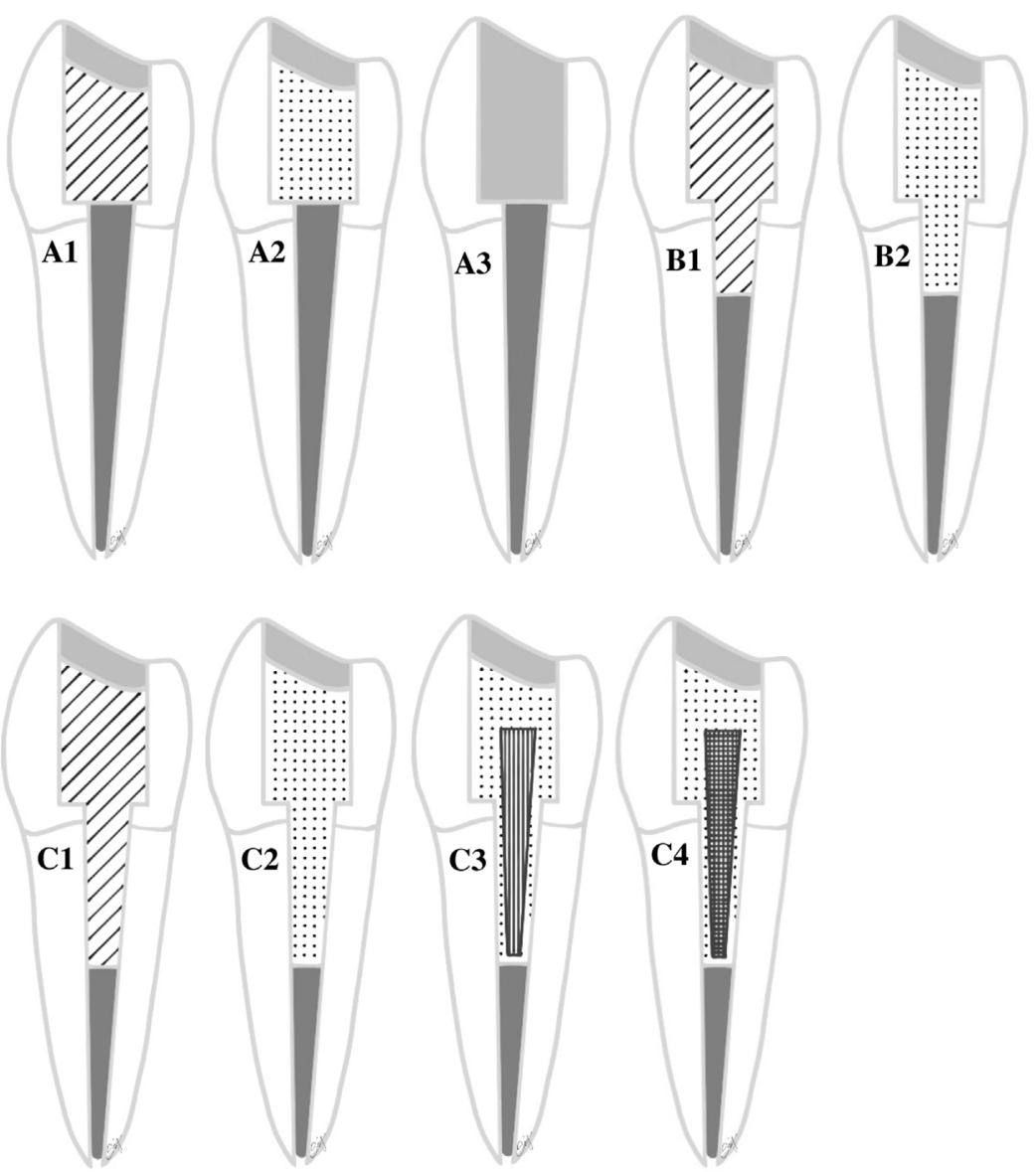

Fig. 1 - Shematic figure representing the test groups (Group A1-C4). Gr. A1: Packable SFRC core; Gr. A2: Flowable SFRC core; Gr. A3: Conventional composite core; Gr. B1: Packable SFRC directly layered as post (3 mm) and core; Gr. B2: Flowable SFRC directly layered as post ( $3 \mathrm{~mm})$ and core; Gr. C1: Packable SFRC directly layered as post (6 mm) and core; Gr. C2: Flowable SFRC directly layered as post (6 mm) and core; Gr. C3: Individually-made unidirectional FRC post luted by flowable SFRC; Gr. C4: Conventional unidirectional FRC post luted by flowable SFRC.

USA) and cleaned with alcohol after try in. The posts received silanization of the surface (Ceramic Primer, GC Europe, Leuven, Belgium) following the manufacturer's recommendation. After silanization, the post surface was bonded with the same bonding agent used for the cavity. Luting of the posts and the core build-up was performed with flowable SFRC. Flowable SFRC was applied in an approx. $4 \mathrm{~mm}$ thick layer into the post space. After insertion of the post, light curing was performed for $60 \mathrm{~s}$. The coronal portion of the cavity was restored as described in Group A2.

Finally, for all restored specimens, glycerine gel (DeOx Gel, Ultradent Products Inc., Orange, CA, USA) was applied and final polymerization from each side for $40 \mathrm{~s}$ was performed. The restorations were finished with a fine granular diamond burr (FG 7406-018, Jet Diamonds, USA and FG 249-F012, Horico, Germany) and aluminum oxide polishers (OneGloss PS Midi, Shofu Dental GmbH, Ratingen, Germany).

\subsection{Mechanical loading of the specimen}

The restored specimens were stored in distilled water at 37 ${ }^{\circ} \mathrm{C}$ for a week. To simulate the periodontal ligament, the root surface of each tooth was coated with a layer of liquid latex separating material (Rubber-Sep, Kerr, Orange, CA) prior to embedding. Specimens were embedded in methacrylate resin (Technovit 4004, Heraeus-Kulzer) at $2 \mathrm{~mm}$ from the cementoenamel junction (CEJ) to simulate the bone level. For mechanical testing, the restored specimens were submitted to an accelerated fatigue-testing protocol [31] by a hydraulic testing machine (Instron ElektroPlus E3000, Norwood, MA, USA) at an angle of 135 degrees to the long axis of each tooth. Testing was carried out in two parts. During the first part of testing (simulation of normal forces) cyclic isometric loading was applied on the triangular ridge of the buccal cusp of the tooth using a round-shaped metallic tip (with a diameter of $5 \mathrm{~mm}$ ). The palatal cusp was slightly reduced to aid the propoer positioning of the testing tip. A cyclic load was applied at a frequency of $5 \mathrm{~Hz}$, starting with gradually increasing static loading till $100 \mathrm{~N}$ in $5 \mathrm{~s}$, followed by cyclic loading in $100 \mathrm{~N}$ steps, up to $500 \mathrm{~N}, 5000$ cycles per step. The specimens were loaded until fracture occurred or 25,000 cycles were reached. The total number of survived cycles were recorded for each specimen for the survival analyses. 
The specimens that survived 25,000 cycles were then loaded with extremely high forces simulating parafunction (clenching or bruxism). During this part of the testing, cyclic isometric loading was continued. Cyclic load was applied at a frequency of $5 \mathrm{~Hz}$, continuing with gradually increasing static loading up to $600 \mathrm{~N}$ in $5 \mathrm{~s}$, followed by cyclic loading in $100 \mathrm{~N}$ steps, up to $1000 \mathrm{~N}, 5000$ cycles per step. The specimens were loaded until fracture occurred or 30,000 cycles were reached (within this second phase). The total number of survived cycles were recorded for each specimen for the survival analyses.

The failed specimens were visually examined under an optical microscope for the type, location and direction of failure, with two-examiner agreement. According to Scotti and co-workers, a distinction was made between repairable and irrepairable fractures, where a repairable fracture is above the CEJ, meaning that in case of fracture, the tooth can be restored, while an irrepairable fracture extends below the CEJ and the tooth is likely to be extracted [33].

\subsection{Microgap detremination test}

Four groups (C1-4), each consisting of 5 endodontically treated and restored teeth, were investigated in the microgap detremination test. The teeth $(n=20)$ were restored in the same way as mentioned earlier. Teeth were sectioned mid-sagitally in the mesio-distal plane using a ceramic cutting disc operating at a speed of $100 \mathrm{rpm}$ (Struers, Glasgow, Scotland) under water cooling. In each group, one of the sectioned restoration that contains the post was further grind and polish using \#4000-grit silicon carbide papers at $300 \mathrm{rpm}$ under water cooling using an automatic grinding machine (Rotopol-1; Struers, Copenhagen, Denmark). Then, sectioned teeth were painted with permanent marker, and polish gently for few seconds. The dye penetration along post/core margins of each section was evaluated independently using a stereo-microscope (Heerbrugg M3Z, Heerbrugg, Switzerland) at a magnification of $6.5 \mathrm{x}$ and the extent of dye penetration was recorded in $\mathrm{mm}$ as a percentage of the total margin length [34].

\subsection{Microhardness test}

Microhardness of luting composite inside the canal was measured using a Struers Duramin hardness microscope (Struers, Copenhagen, Denmark) with a 40 objective lens and a load of $1.96 \mathrm{~N}$ applied for $10 \mathrm{~s}$. Each sectioned restoration was subjected to 5 indentations on the top (coronal part) and the bottom (apical part) of the canal for indication of polymerization $[35,36]$. The diagonal length impressions were measured and Vickers values were converted into microhardness values by the machine. Microhardness was obtained using the following equation:

$\mathrm{H}=\frac{1854.4 \times \mathrm{P}}{d^{2}}$

where $\mathrm{H}$ is Vickers hardness in $\mathrm{kg} / \mathrm{mm}^{2}, \mathrm{P}$ is the load in grams and $d$ is the length of the diagonals in $\mu \mathrm{m}$.

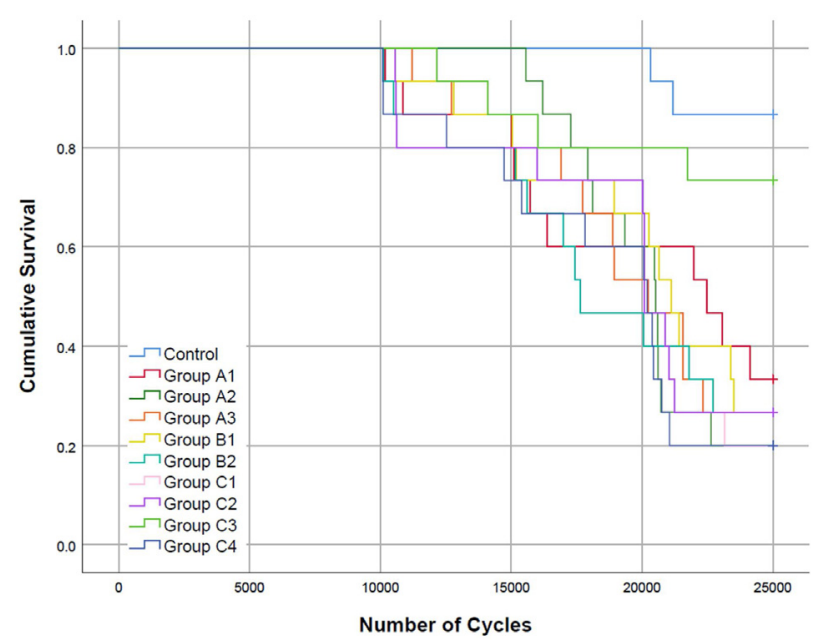

Fig. 2 - Fatigue resistance survival curves (Kaplan-Meier survival estimator) for all tested group loaded with a force of magnitude 100-500 N.

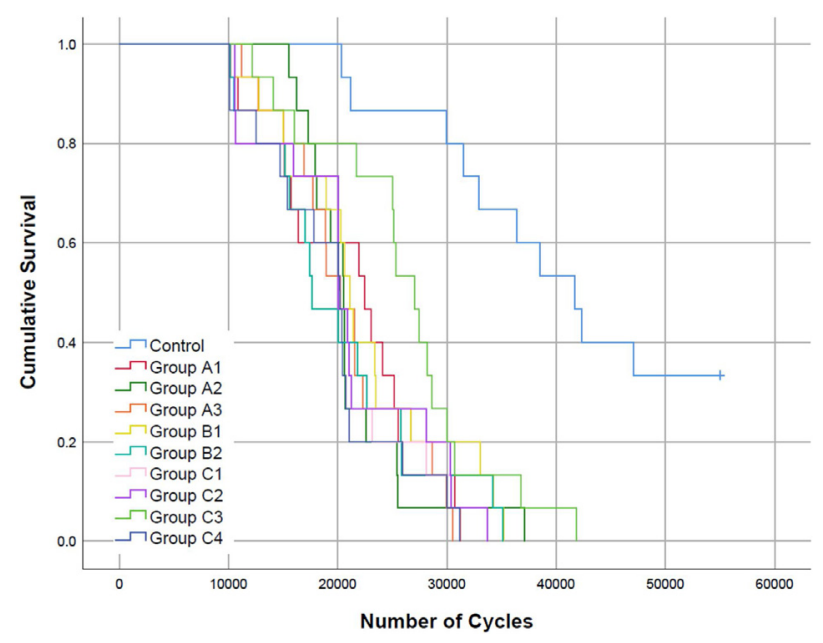

Fig. 3 - Fatigue resistance survival curves (Kaplan-Meier survival estimator) for all tested groups loaded with a force of magnitude $600-1000 \mathrm{~N}$.

\subsection{Statistical analysis}

Statistical analyses were performed in SPSS 21.0 (IBM, USA). Groups were defined according to the method of restoration (or the lack thereof for the control group). The number of survived cycles was analyzed descriptively for each group and with the Kaplan-Meier method across the groups (with the Breslow test for the pairwise analyses). The frequency of restorable and non-restorabe fractures was calculated for each group.

\section{Results}

The Kaplan-Meier survival curves for the test simulating normal (100-500 N) and parafunctional (600-1000 N) forces are displayed in Figs. 2 and 3 respectively. Table 1 presents the $\mathrm{p}$ values for group-wise comparisons in the test simulating nor- 


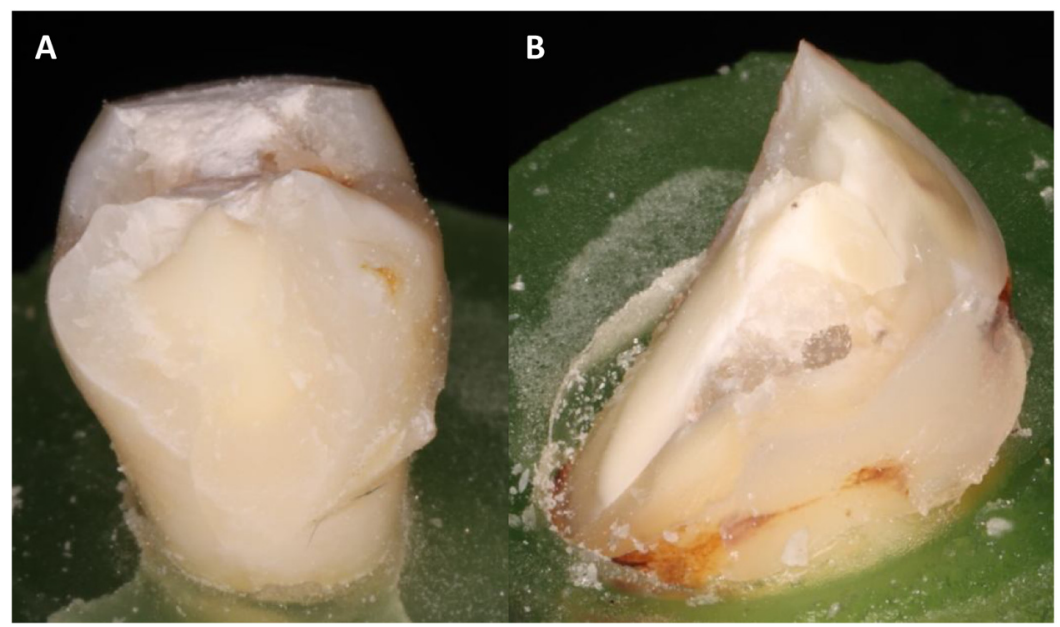

Fig. 4 - Photographs of repairable (A) and irrepairable (B) fracture pattern of the tested specimens.

mal forces, while Table 2 presents the $\mathrm{p}$ values for group-wise comparisons in the test simulating parafunctional forces.

In the test simulating normal forces the survival rate of Group C3 was not showing significant difference $(p>0.05)$ from Group A1 or the control group (intact teeth). The rest of the groups had significantly lower survival rates compared to both Group C3 and the control group.

In the test simulating parafunctional forces for the specimens survived the first phase of mechanical testing $(n=54)$, the survival rate of the control group showed significantly higher survival $(p<0.05)$ compared to the rest of the tested groups. The restored groups present in the second phase of the test did not differ significantly $(p>0.05)$ from each other in terms of survival.

All restored groups showed dominantly irrepairable fractures, whereas only the control group presented almost exclusively repairable fractures (Table 3 and Fig. 4).

The average values with SD of microgap percentage at post/core-tooth interface of four groups (C1-C4) are illustrated in Fig. 5. Values revealed that post/core restorations made of directly layered packable SFRC (Group C1) had a less microgap (19.1\%) than other tested groups. While, Group C3 exhibited the highest number of microgap (55.9\%) at the studied interphase within the root canal (Fig. 5).

Concerning the microhardness values for the packable and flowable SFRCs at the bottom (apical) of the root canal, flowable SFRC (C2-C4) showed higher microhardness values (56.9 $\mathrm{VH})$ as well as lower difference among the microhardness values at the coronal and at the apical part of the root canal (Fig. 6).

\section{Discussion}

One of the main goals of post-endodontic restoration of RCT teeth is restoring lost resistance to masticatory load [37]. In this investigation, upper RCT premolars with MO cavities were selected as they present an unfavorable anatomy in crown to root ratio and crown volume, which makes them at greater risk to cusp fractures compared to other posterior teeth when subjected to occlusal load [13]. Furthermore, premolars are

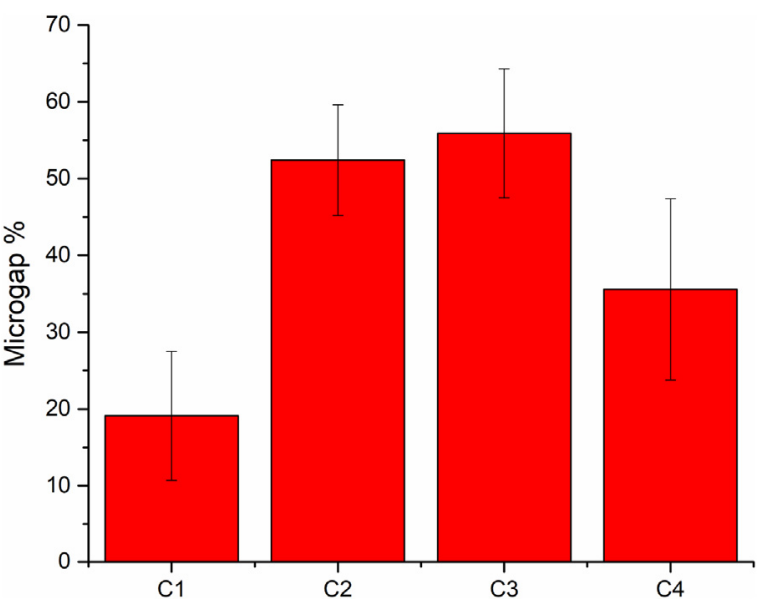

Fig. 5 - Mean percentage of microgap observed in different groups from total post/core-tooth interface length after staining. Vertical lines represent standard deviation.

exposed to more detrimental lateral forces than molars during mastication, namely a combination of compressive and shear forces that raises the possibility of cusp fracture [38]. The tested specimens loaded with an angle (45 degree to the long axis of the tooth), which seems to be the worst-case scenario in regards to the fracture resistance of RCT teeth as described by Wandscher and his colleagues [39].

According to Ferrario et al., the normal biting force that develops during a single tooth bite is approximately 250-290 $\mathrm{N}$ for the first and second premolars in healthy young male adults [40]. This is in accordance with the findings of Jantarah et al., who reported the normal biting force for maxillary premolars to be in the range between 100-300 N [41]. However, higher biting forces have to be predicted in individuals with functional disturbances, such as clenching or bruxism where biting force can be as high as $520-800 \mathrm{~N}[42,43]$. It was on the basis of these published values that we divided our test protocol into 2 phases, where the first phase simulated normal biting forces (up to $500 \mathrm{~N}$ ) and the second phase simulated extremely high forces (up to $1000 \mathrm{~N}$ ). The 
Table 1 - $p$ values of pairwise log-rank post-hoc comparisons among tested groups loaded with a force of magnitude 100-500 N (Kaplan-Meier survival estimator

followed by log-rank test for cycles until failure or the end of the fatigue loading).

$\begin{array}{lllll}\text { A1 } & \text { A2 } & \text { A3 } & \text { B1 } & \text { B2 }\end{array}$

C1

C2

C3

C4

control

Gr. Chi-Square Sig. Chi-Square Sig. Chi-Square Sig. Chi-Square Sig. Chi-Square Sig. Chi-Square Sig. Chi-Square Sig. Chi-Square Sig. Chi-Square Sig. Chi-Square Sig.

\begin{tabular}{|c|c|c|c|c|c|c|c|c|c|c|c|}
\hline A1 & & 0.028 & 0.8660 .074 & 0.7850 .053 & 0.8180 .370 & 0.5430 .448 & 0.5030 .276 & 0.6003 .252 & 0.0711 .099 & 0.2948 .658 & 0.003 \\
\hline A2 & 0.028 & 0.866 & 0.035 & 0.8520 .126 & 0.7230 .736 & 0.3910 .007 & 0.9340 .000 & 0.9834 .509 & 0.0340 .918 & 0.33813 .778 & 0.000 \\
\hline A3 & 0.074 & 0.7850 .035 & 0.852 & 0.085 & 0.7700 .367 & 0.5450 .097 & 0.7550 .053 & 0.8194 .305 & 0.0380 .471 & 0.49311 .571 & 0.001 \\
\hline B1 & 0.053 & 0.8180 .126 & 0.7230 .085 & 0.770 & 0.419 & 0.5170 .416 & 0.5190 .230 & 0.6314 .294 & 0.0381 .134 & 0.28710 .864 & 0.001 \\
\hline B2 & 0.370 & 0.5430 .736 & 0.3910 .000 & 0.5450 .419 & 0.517 & 0.229 & 0.6320 .318 & 0.5735 .080 & 0.0240 .004 & 0.95012 .320 & 0.000 \\
\hline C1 & 0.448 & 0.5030 .007 & 0.9340 .471 & 0.7550 .416 & 0.5190 .229 & 0.632 & 0.007 & 0.9346 .367 & 0.0120 .247 & 0.61914 .155 & 0.000 \\
\hline C2 & 0.276 & 0.6000 .000 & 0.9830 .735 & 0.8190 .230 & 0.6310 .318 & 0.5730 .007 & 0.934 & 5.312 & 0.0210 .315 & 0.57512 .320 & 0.000 \\
\hline C3 & 3.252 & 0.0714 .509 & 0.0340 .140 & 0.0384 .294 & 0.0385 .080 & 0.0246 .367 & 0.0125 .312 & 0.021 & 6.619 & 0.0101 .019 & 0.313 \\
\hline $\mathrm{C} 4$ & 1.099 & 0.2940 .918 & 0.3380 .121 & 0.4931 .134 & 0.2870 .004 & 0.9500 .247 & 0.6190 .315 & 0.5756 .619 & 0.010 & 15.017 & 0.000 \\
\hline Con & 8.658 & 0.00313 .778 & 0.00015 .059 & 0.00110 .864 & 0.00112 .320 & 0.00014 .155 & 0.00012 .320 & 0.0001 .019 & 0.31315 .017 & 0.000 & \\
\hline
\end{tabular}

Table 2 - p values of pairwise log-rank post-hoc comparisons among tested groups loaded with a force of magnitude 600-1000 N (Kaplan-Meier survival estimator

followed by log-rank test for cycles until failure or the end of the fatigue loading).

$\begin{array}{lllll}\text { A1 } & \text { A2 } & \text { A3 } & \text { B1 } & \text { B2 }\end{array}$

B2

C1

$\mathrm{C} 2$

C3

C4

control

Gr. Chi-Square Sig. Chi-Square Sig. Chi-Square Sig. Chi-Square Sig. Chi-Square Sig. Chi-Square Sig. Chi-Square Sig. Chi-Square Sig. Chi-Square Sig. Chi-Square Sig.

\begin{tabular}{|c|c|c|c|c|c|c|c|c|c|c|c|}
\hline A1 & & 0.022 & 0.8810 .235 & 0.6283 .938 & 0.0470 .928 & 0.3361 .000 & 0.3170 .928 & 0.3360 .029 & 0.8660 .184 & 0.6680 .022 & 0.000 \\
\hline A2 & 0.022 & 0.881 & 0.533 & 0.4650 .533 & 0.4650 .533 & 0.4650 .429 & 0.5130 .533 & 0.4650 .006 & 0.9380 .429 & 0.5138 .008 & 0.000 \\
\hline A3 & 0.235 & 0.6280 .533 & 0.465 & 1.391 & 0.2380 .000 & 1.0000 .471 & 0.4930 .735 & 0.3910 .140 & 0.7080 .121 & 0.72815 .059 & 0.000 \\
\hline B1 & 3.938 & 0.0470 .533 & 0.4651 .391 & 0.238 & 0.735 & 0.3910 .500 & 0.4800 .750 & 0.3860 .973 & 0.3242 .207 & 0.1375 .255 & 0.000 \\
\hline B2 & 0.928 & 0.3360 .533 & 0.4650 .000 & 1.0000 .735 & 0.391 & 0.000 & 1.0000 .000 & 1.0000 .065 & 0.7990 .000 & 1.0008 .290 & 0.004 \\
\hline C1 & 1.000 & 0.3170 .429 & 0.5130 .471 & 0.4930 .500 & 0.4800 .000 & 1.000 & 0.032 & 0.8580 .624 & 0.4300 .409 & 0.5227 .877 & 0.005 \\
\hline C2 & 0.928 & 0.3360 .533 & 0.4650 .735 & 0.3910 .750 & 0.3860 .000 & 1.0000 .032 & 0.858 & 0.952 & 0.3290 .500 & 0.4809 .587 & 0.002 \\
\hline C3 & 0.029 & 0.8660 .006 & 0.9380 .140 & 0.7080 .973 & 0.3240 .065 & 0.7990 .624 & 0.4300 .952 & 0.329 & 0.137 & 0.71214 .569 & 0.000 \\
\hline C4 & 0.184 & 0.6680 .429 & 0.5130 .121 & 0.7282 .207 & 0.1370 .000 & 1.0000 .409 & 0.5220 .500 & 0.4800 .137 & 0.712 & 12.129 & 0.000 \\
\hline Con & 17.069 & 0.0008 .008 & 0.00515 .059 & 0.0005 .255 & 0.0228 .290 & 0.0047 .877 & 0.0059 .587 & 0.00214 .569 & 0.00012 .129 & 0.000 & \\
\hline
\end{tabular}




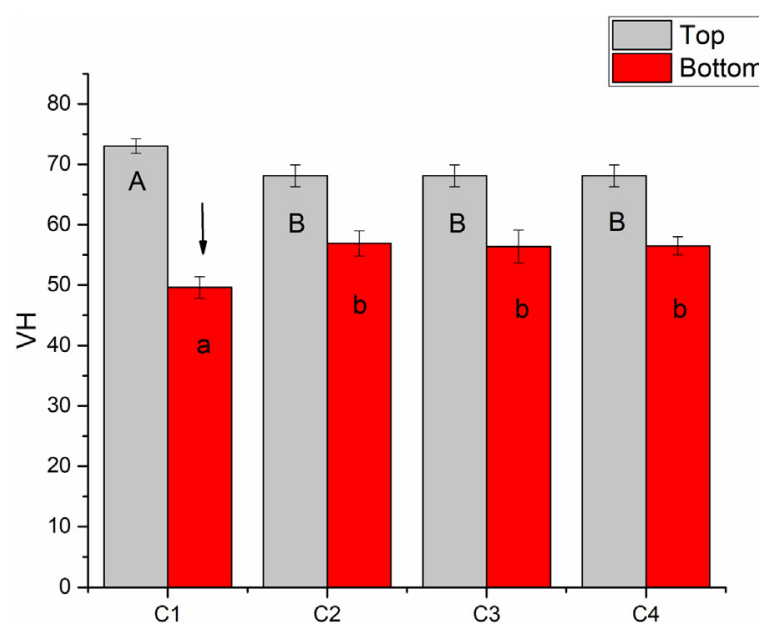

Fig. 6 - Microhardness (VH) mean values for packable and flowable SFRCs at the top (coronal) and bottom (apical) part of the root canal. Arrows above the columns indicate VH of this group dropped below $80 \%$ of the coronal part value. Vertical lines represent standard deviation.

latter aspect requires to be taken into consideration because temporomandibular disorders are highly prevalent in Western societies [44]. Occlusal load is a key factor in the successful treatment of root-filled teeth and it is crucial for the clinician to know if the patient has parafunctional movements [45].

In our study, only specimens restored with an individuallymade unidirectional FRC post luted with flowable SFRC (Group C3) showed significantly higher survival compared to the rest of the restored groups when exposed to normal biting forces. The only exception was the Group A1, which did not differ significantly from the C3 group in terms of survival. The individually-made post used in Group C3 is made of unidirectional fibers (E-glass) impregnated with a combination of bisphenol A-glycidyl methacrylate as the cross-linked phase and polymethyl methacrylate as a linear phase, which together form a semi-interpenetrating polymer network (semi-IPN) [46]. As the semi-IPN structure contains both cross-linked and linear polymer phases, it ensures a stable adhesion to resin materials used for luting. Logically, this could possibly influence the fracture resistance of the restoration. In the study of Doshi et al., teeth restored with the individually-made FRC post presented higher fracture resistance compared to the ones restored with a conventional FRC post [47]. On the contrary, in our previous study the individually-made FRC post did not make a significant difference in regards to fracture resistance compared to a conventional FRC post [48]. It must be noted that in the mentioned study the teeth were decoronated premolar teeth (not MO cavities), and also the luting and core build-up material was a conventional particulate filled dual-cure resin, not a fiberreinforced one. The same was found in our latest study where apexified anterior teeth were used [31]. In this present study, the superior resistance of the specimens restored with the individually-made FRC post might be attributed to the flowable SFRC used for post luting and subsequent core build-up. The flowable SFRC forms a unit with the individually-made post due to the semi-IPN polymer matrix of this post. Studies have demonstrated increased bond strength between the individually-made FRC post and composite resin materials compared to conventional FRC post [26]. To our knowledge, flowable SFRC has not been used to lute posts into root canals. This indication could be important from a biomimetic point a view. FRC posts usually do not have a perfect fit inside the root due to the irregular anatomy and individual cross section of the root canal. As a result, it is usually the mechanically inferior luting material that fills out the gaps between the root canal walls and the post, acting as the interfacial medium between them. As detrimental tensile stresses occur on the surfaces of the root canal walls, the restorative material placed with the intention of stress-bearing should be luted directly to them with close contact [49]. As highlighted by Le BellRönnlöf et al., if the conventional FRC post is inserted in the most central part of the post position (i.e. the neutral axis of the tooth), the post is not ideally placed with respect to biomechanics if reinforcement is the intended results [49]. Beside their superior resistance in the normal force range $(100-500 \mathrm{~N})$, specimens restored with the individually-made FRC post combined with flowable SFRC did not show statistically significant difference compared to controls (Table 1). Fiber-reinforced materials are increasingly used for crackarresting and reinforcement in high stress-bearing areas. In the Bioblock technique, SFRC is directly and tightly fitted to the wall of root canal, excluding the shortcomings of the usage of luting cement or the biomechanically improper positioning of the FRC post, thus theoretically eliminating all damaging tensile stresses created when the restoration is loaded [30]. This enables the clinician to fill and restore any root canal with irregular cross section deemed not ideal for FRC post insertion. With the Bioblock technique, the amount of fibers can be maximized also in the critical cervical area of the tooth, which seems to be important regarding future stress accumulation [50]. Not less importantly, the Bioblock technique minimizes the number of interfaces within the restoration-tooth complex, which has been shown to be beneficial as interfaces increases the amount of stress within this unit [51]. Interestingly, in this study neither the normal Bioblock technique (Group C1), nor its modification (extending only $3 \mathrm{~mm}$ into the canal; Group B1) achieved survival comparable to Group C3 or intact teeth. In one of our previous studies, the Bioblock technique yielded higher fracture resistance compared to teeth restored with a conventional FRC post. However, in that study we tested the restoration of MOD cavities in premolars and static loading was applied [30]. Our current findings are in accordance with previous studies showing that restorations prepared with the Bioblock technique failed to reach fracture resistance or survival comparable to intact teeth, in MOD RCT premolars [30] and apexified anterior teeth [31], respectively. The performance of fiber reinforcement relies on many factors, namely the used resins, the thickness, length, position and the orientation of fibers, the fibers aspect ratio, the adhesion of the polymer matrix and fibers, and the impregnation of the fibers into the resin [52]. The fiber aspect ratio refers to the length of the fiber compared to the diameter of the fiber $(\mathrm{l} / \mathrm{d})$. The fiber aspect ratio is of major importance in the case of modern fiber-reinforced materials since it affects flexural modulus, tensile strength, and the reinforcing 
Table 3 - The distribution of fracture pattern among the tested groups $(n=15)$.

\begin{tabular}{llllllllllll} 
Fracture pattern & A1 & A2 & A3 & B1 & B2 & C1 & C2 & C3 & C4 & Control \\
repairable & 1 & 3 & 2 & 1 & 0 & 1 & 0 & 0 & 0 & 12 & 15 \\
irrepairable & 14 & 12 & 13 & 14 & 15 & 14 & 15 & 15 & 15 & 3 \\
\hline
\end{tabular}

efficiency of the material $[53,54]$. While packable SFRC contains millimeter-long fibers, the fibers in the flowable SFRC are micrometer-long. Even with the shorter fibers incorporated in the flowable SFRC, the fiber aspect ratio is within the range of 30-94 [55], thus offering reinforcement to the materials and likely to the adhered dental tissues. Curiously, the Bioblock technique did not allow superior survival compared to the other groups and was significantly weaker compared to intact teeth, even with the flowable SFRC. This is against our previous findings in anterior apexified teeth where the Bioblock technique with flowable SFRC was the only tested restorative technique yielded survival comparable to intact teeth [31].

Regarding the fracture behavior and load-bearing capacity of SFRC restorations, Lassila et al., stated that the optimal thickness of the surface conventional composite over the SFRC-core is between 0.5-1 mm [56]. Assuming that reinforcement role of the SFRC-core is built upon the mechanism of a crack-stopper, the length from the surface of the stress starting point to the SFRC-core is of importance. Thus, the veneered conventional composite thickness might contribute to the crack propagation and the survival rate of the restorations. This is consistent with earlier investigations which showed the importance of how thick SFRC and conventional surface layers should be applied [57,58].

Most dental practitioners regularly restore RCT upper premolars with conventional fiber posts, but this approach is a matter of debate [4]. There are studies to indicate that RCT upper premolars without a fiber post show similar fracture resistance to those restored with a post [59-61], while other studies showed superior results when a conventional FRC post was used compared to a composite filling alone [62,63]. In our present setup, there was no difference between teeth restored with a conventional composite filling alone (Group A3) or with a conventional FRC post and flowable SFRC (Group C4). The survival of the groups restored with the latter two techniques was also significantly lower compared to intact teeth. Our current findings are also in accordance with those of Shah et al. [37], and Nothdurft et al. [16], showing that RCT premolars with MO cavities cannot be reinforced with a composite filling only, as these teeth do not have the same fracture resistance as intact teeth. As for testing in the extreme force range, none of the tested techniques allowed survival comparable to intact teeth. This is important to consider when treating patients who could possibly overload the restoration due to clenching or bruxism. Regarding the fracture patterns, all specimens in all groups showed predominantly irreparable fractures, except for the control group, where the fractures were predominantly reparable.

Considering the adaptation of the used materials within the root canal appeares to be very important, gap formation was also evaluated with a microgap determing test for the packable and flowable SFRCs (Fig. 5). The packable SFRC (Group C1) had notably good adaptation to the canal walls than other tested groups (C2-C4), which was in agreement with our pre- vious findings [30,31]. Though the adaptation of the packable SFRC to the canal walls was ideal, voids were seen within the material itself. These voids could be due to poor condensation of the material inside the tighten space, or entrapment of air when applying the thick material into the canal. The authors' opinion is that these voids could contribute in reducing the shrinkage stress during the polymerization and this might decrease the microgaps at interfaces. Infact, this has been suggested also earlier when the influence of FRC in regular filling application was studied [64].

In line with previous findings and due to the higher volumetric shrinkage of the flowable SFRC, the microgap formation at the examined interphase in the root canal with flowable SFRC (Group C2-C4), was not so perfect.

Microhardness test was carried out in order to assess the curing of SFRCs inside the root canal. The data revealed that SFRCs used in the coronal part of the canal had superior microhardness compared to the apical part of the same canal, demonstrating enhance curing due to higher intensity of light polymerization. In the crucial apical part of the canal, flowable SFRC (C2-C4) showed higher microhardness values and also lower difference between the microhardness measured at the apical and at the coronal parts of the root canal (Fig. 6). This is in line with previous results showing that SFRC can be light-cured inside the canal [29-31]. This is resulting from both the translucency of the material and the fact that the randomly oriented fibers within it may conduct and scatter the light over longer distances [65]. It has been shown that refraction index of glass fibers and dimatehacrylate resin matrix during its curing phase benefits light scattering and improves photopolymerization [66].

To mimic more clinical environment and to have perfect view of restorative material/design behavior under clinical conditions, fatigue survival after long-term water storage and thermal aging should also be taken into consideration.

\section{Conclusion}

The restoration of ET premolars with the use of individuallymade FRC post and SFRC as luting-core material showed promising achievement regarding fatigue-resistance and survival.

\section{REFERENCES}

[1] Zavattini A, Feitosa VP, Manocci F, Foschi F, Babbar A, Luzi A et al. Bonding ability of experimental resin-based materials containing (ion-releasing)-microfillers applied on water-wet or ethanol-wet root canal dentine. Int J Adhes Adhes 2014;54:214-23, http://dx.doi.org/10.1016/j.ijadhadh.2014.06.007.

[2] Al-Omiri MK, Mahmoud AA, Rayyan MR, Abu-Hammad O. Fracture resistance of teeth restored with post-retained 
restorations: an overview. J Endod 2010;36(9):1439-49, http://dx.doi.org/10.1016/j.joen.2010.06.005.

[3] Reeh ES, Messer HH, Douglas WH. Reduction in tooth stiffness as a result of endodontic and restorative procedures. J Endod 1989;15(11):512-6, http://dx.doi.org/10.1016/S0099-2399(89)80191-8.

[4] Mohammadi N, Kahnamoii MA, Yeganeh PK, Navimipour EJ. Effect of fiber post and cusp coverage on fracture resistance of endodontically treated maxillary premolars directly restored with composite resin. J Endod 2009;35(10):1428-32, http://dx.doi.org/10.1016/j.joen.2009.07.010.

[5] Yamada Y, Tsubota Y, Fukushima S. Effect of restoration method on fracture resistance of endodontically treated maxillary premolars. Int J Prosthodont 2004;17(1): 94-8.

[6] Sorrentino R, Di Mauro MI, Ferrari M, Leone R, Zarone F. Complications of endodontically treated teeth restored with fiber posts and single crowns or fixed dental prostheses-a systematic review. Clin Oral Investig 2016;20(7):1449-57, http://dx.doi.org/10.1007/s00784-016-1919-8.

[7] Oskoee PA, Ajami AA, Navimipour EJ, Oskoee SS, Sadjadi J. The effect of three composite fiber insertion techniques on fracture resistance of root-filled teeth. J Endod 2009;35(3):413-6, http://dx.doi.org/10.1016/j.joen.2008.11.027.

[8] Wu Y, Cathro P, Marino V. Fracture resistance and pattern of the upper premolars with obturated canals and restored endodontic occlusal access cavities. J Biomed Res 2010;24(6):474-8, http://dx.doi.org/10.1016/S1674-8301(10)60063-2.

[9] El-Helali R, Dowling AH, McGinley EL, Duncan HF, Fleming GJ. Influence of resin-based composite restoration technique and endodontic access on cuspal deflection and cervical microleakage scores. J Dent 2013;41(3):216-22, http://dx.doi.org/10.1016/j.jdent.2012.11.002.

[10] Plotino G, Buono L, Grande NM, Lamorgese V, Somma F. Fracture resistance of endodontically treated molars restored with extensive composite resin restorations. J Prosthet Dent 2008;99(3):225-32, http://dx.doi.org/10.1016/S0022-3913(08)60047-5.

[11] Belli S, Erdemir A, Yildirim C. Reinforcement effect of polyethylene fibre in root-filled teeth: comparison of two restoration techniques. Int Endod J 2006;39(2):136-42, http://dx.doi.org/10.1111/j.1365-2591.2006.01057.x.

[12] Zicari F, De Munck J, Scotti R, Naert I, Van Meerbeek B. Factors affecting the cement-post interface. Dent Mater 2012;28(3):287-97, http://dx.doi.org/10.1016/j.dental.2011.11.003.

[13] Soares PV, Santos-Filho PC, Martins LR, Soares CJ. Influence of restorative technique on the biomechanical behavior of endodontically treated maxillary premolars. Part I: fracture resistance and fracture mode. J Prosthet Dent 2008;99(1):30-7,

http://dx.doi.org/10.1016/S0022-3913(08)60006-2.

[14] Scotti N, Scansetti M, Rota R, Pera F, Pasqualini D, Berutti E. The effect of the post length and cusp coverage on the cycling and static load of endodontically treated maxillary premolars. Clin Oral Investig 2011;15(6):923-9, http://dx.doi.org/10.1007/s00784-010-0466-y.

[15] Bitter K, Noetzel J, Stamm O, Vaudt J, Meyer-Lueckel H, Neumann K, et al. Randomized clinical trial comparing the effects of post placement on failure rate of postendodontic restorations: preliminary results of a mean period of 32 months. J Endod 2009;35(11):1477-82, http://dx.doi.org/10.1016/j.joen.2009.07.026.

[16] Nothdurft FP, Seidel E, Gebhart F, Naumann M, Motter PJ, Pospiech PR. The fracture behavior of premolar teeth with class II cavities restored by both direct composite restorations and endodontic post systems. J Dent
2008;36(6):444-9,

http://dx.doi.org/10.1016/j.jdent.2008.03.004.

[17] Qualtrough AJ, Mannocci F. Tooth-colored post systems: a review. Oper Dent 2003;28(1):86-91.

[18] Soares CJ, Soares PV, de Freitas Santos-Filho PC, Castro CG, Magalhaes D, Versluis A. The influence of cavity design and glass fiber posts on biomechanical behavior of endodontically treated premolars. J Endod 2008;34(8):1015-9, http://dx.doi.org/10.1016/j.joen.2008.05.017.

[19] Stockton L, Lavelle CL, Suzuki M. Are posts mandatory for the restoration of endodontically treated teeth? Endod Dent Traumatol 1998;14(2):59-63, http://dx.doi.org/10.1111/j.1600-9657.1998.tb00810.x.

[20] Trope M, Maltz DO, Tronstad L. Resistance to fracture of restored endodontically treated teeth. Endod Dent Traumatol 1985;1(3):108-11, http://dx.doi.org/10.1111/j.1600-9657.1985.tb00571.x.

[21] Zicari F, Van Meerbeek B, Scotti R, Naert I. Effect of fibre post length and adhesive strategy on fracture resistance of endodontically treated teeth after fatigue loading. J Dent 2012;40(4):312-21, http://dx.doi.org/10.1016/j.jdent.2012.01.006.

[22] Meyenberg K. The ideal restoration of endodontically treated teeth - structural and esthetic considerations: a review of the literature and clinical guidelines for the restorative clinician. Eur J Esthet Dent 2013;8(2):238-68.

[23] Aurélio IL, Fraga S, Rippe MP, Valandro LF. Are posts necessary for the restoration of root filled teeth with limited tissue loss? A structured review of laboratory and clinical studies. Int Endod J 2016;49(9):827-35, http://dx.doi.org/10.1111/iej.12538.

[24] Faria-e-Silva AL, Pedrosa-Filho Cde F, Menezes Mde S, Silveira DM, Martins LR. Effect of relining on fiber post retention to root canal. J Appl Oral Sci 2009;17(6):600-4, http://dx.doi.org/10.1590/s1678-77572009000600012.

[25] D'Arcangelo C, Cinelli M, De Angelis F, D'Amario M. The effect of resin cement film thickness on the pullout strength of a fiber-reinforced post system. J Prosthet Dent 2007;98(3):193-8, http://dx.doi.org/10.1016/S0022-3913(07)60055-9.

[26] Bell AM, Lassila LV, Kangasniemi I, Vallittu PK. Bonding of fibre-reinforced composite post to root canal dentin. J Dent 2005;33(7):533-9, http://dx.doi.org/10.1016/j.jdent.2004.11.014.

[27] Chieruzzi M, Pagano S, Pennacchi M, Lombardo G, D’Errico P, Kenny JM. Compressive and flexural behaviour of fibre reinforced endodontic posts. J Dent 2012;40(11):968-78, http://dx.doi.org/10.1016/j.jdent.2012.08.003.

[28] Garoushi S, Vallittu PK, Lassila LV. Continuous and short fiber reinforced composite in root post-core system of severely damaged incisors. Open Dent J 2009;3:36-41, http://dx.doi.org/10.2174/1874210600903010036.

[29] Forster A, Sáry T, Braunitzer G, Fráter M. In vitro fracture resistance of endodontically treated premolar teeth restored with a direct layered fiber-reinforced composite post and core. J Adhes Sci Technol 2016;31, 1454-66. https://doi.org/10.1080/01694243.2016.1259758.

[30] Fráter M, Lassila L, Braunitzer G, Vallittu PK, Garoushi S. Fracture resistance and marginal gap formation of post-core restorations: influence of different fiber-reinforced composites. Clin Oral Investig 2020;24(1):265-76, http://dx.doi.org/10.1007/s00784-019-02902-3.

[31] Fráter M, Sáry T, Néma V, et al. Fatigue failure load of immature anterior teeth: influence of different fiber post-core systems. Odontology 2020, http://dx.doi.org/10.1007/s10266-020-00522-y.

[32] Schneider SW. A comparison of canal preparations in straight and curved root canals. Oral Surg Oral Med Oral 
Pathol 1971;32(2):271-5,

http://dx.doi.org/10.1016/0030-4220(71)90230-1.

[33] Scotti N, Coero Borga FA, Alovisi M, Rota R, Pasqualini D, Berutti E. Is fracture resistance of endodontically treated mandibular molars restored with indirect onlay composite restorations influenced by fibre post insertion? J Dent 2012;40(10):814-20,

http://dx.doi.org/10.1016/j.jdent.2012.06.005.

[34] Vallittu PK. Impregnation of glass fibres with polymethylmethacrylate by using a powder coating method. Appl Compos Mater 1995;2:51-8.

[35] Le Bell A-M, Tanner J, Lassila LVJ, Kangasniemi I, Vallittu PK. Depth of light initiated polymerization of glass fiber reinforced composite in a simulated root canal. Int $J$ Prosthodont 2003;16:403-8.

[36] Aromaa M, Vallittu PK. Delayed post-curing stage and oxygen inhibition of free-radical polymerization of dimethacrylate resin. Dent Mater 2018;34(9): 1247-52.

[37] Shah S, Shilpa-Jain DP, Velmurugan N, Sooriaprakas C, Krithikadatta J. Performance of fibre reinforced composite as a post-endodontic restoration on different endodontic cavity designs- an in-vitro study. J Mech Behav Biomed Mater 2020;104:103650, http://dx.doi.org/10.1016/j.jmbbm.2020.103650.

[38] Robbins JW. Restoration of the endodontically treated tooth. Dent Clin North Am 2002;46(2):367-84, http://dx.doi.org/10.1016/s0011-8532(01)00006-4.

[39] Wandscher VF, Bergoli CD, Limberger IF, Ardenghi TM, Valandro LF. Preliminary results of the survival and fracture load of roots restored with intracanal posts: weakened vs nonweakened roots. Oper Dent 2014;39(5):541-55, http://dx.doi.org/10.2341/12-465.

[40] Ferrario VF, Sforza C, Serrao G, Dellavia C, Tartaglia GM. Single tooth bite forces in healthy young adults. J Oral Rehabil 2004;31(1):18-22, http://dx.doi.org/10.1046/j.0305-182x.2003.01179.x.

[41] Jantarat J, Palamara JE, Messer HH. An investigation of cuspal deformation and delayed recovery after occlusal loading. J Dent 2001;29(5):363-70, http://dx.doi.org/10.1016/s0300-5712(01)00018-5.

[42] Nishigawa K, Bando E, Nakano M. Quantitative study of bite force during sleep associated bruxism. J Oral Rehabil 2001;28(5):485-91, http://dx.doi.org/10.1046/j.1365-2842.2001.00692.x.

[43] Rahman H, Singh S, Chandra A, Chandra R, Tripathi S. Evaluation of fracture resistance of endodontically treated teeth restored with composite resin along with fibre insertion in different positions in vitro. Aust Endod J 2016;42(2):60-5, http://dx.doi.org/10.1111/aej.12127.

[44] Barbosa Tde S, Miyakoda LS, Pocztaruk Rde L, Rocha CP, Gavião MB. Temporomandibular disorders and bruxism in childhood and adolescence: review of the literature. Int J Pediatr Otorhinolaryngol 2008;72(3):299-314, http://dx.doi.org/10.1016/j.ijporl.2007.11.006.

[45] Zarow M, Ramírez-Sebastià A, Paolone G, de Ribot Porta J, Mora J, Espona J, et al. A new classification system for the restoration of root filled teeth. Int Endod J 2018;51(3):318-34, http://dx.doi.org/10.1111/iej.12847.

[46] Amižić IP, Miletić I, Baraba A, Fan Y, Nathanson D. In vitro retention of prefabricated and individually formed posts: a pilot study. J Prosthet Dent 2018;120(4):553-7, http://dx.doi.org/10.1016/j.prosdent.2018.04.011.

[47] Doshi P, Kanaparthy A, Kanaparthy R, Parikh DS. A Comparative Analysis of Fracture Resistance and Mode of Failure of Endodontically Treated Teeth Restored Using Different Fiber Posts: An In VitroStudy. J Contemp Dent Pract 2019;20(10):1195-9.
[48] Fráter M, Forster A, Jantyik Á, Braunitzer G, Nagy K, Grandini $S$. In vitro fracture resistance of premolar teeth restored with fibre-reinforced composite posts using a single or a multi-post technique. Aust Endod J 2017;43(1):16-22, http://dx.doi.org/10.1111/aej.12150.

[49] Le Bell-Rönnlöf AM, Lassila LV, Kangasniemi I, Vallittu PK. Load-bearing capacity of human incisor restored with various fiber-reinforced composite posts. Dent Mater 2011;27(6), e107-115. doi: 10.1016/j.dental.2011.02.009.

[50] Vallittu PK. Are we misusing fiber posts? Guest editorial. Dent Mater 2016;32(2):125-6.

[51] Belli S, Eraslan O, Eskitascioglu G, Karbhari V. Monoblocks in root canals: a finite elemental stress analysis study. Int Endod J 2011;44(9):817-26.

[52] Garoushi S, Gargoum A, Vallittu PK, Lassila L. Short fiber-reinforced composite restorations: a review of the current literature. J Investig Clin Dent 2018;9(3), e12330. doi: 10.1111/jicd.12330.

[53] Bijelic-Donova J, Garoushi S, Lassila LV, Keulemans F, Vallittu PK. Mechanical and structural characterization of discontinuous fiber-reinforced dental resin composite. J Dent 2016;52:70-8, http://dx.doi.org/10.1016/j.jdent.2016.07.009.

[54] Vallittu PK. High aspect ratio fillers: fiber-reinforced composites and their anisotropic properties. Dent Mater 2014;31:1-7.

[55] Lassila L, Keulemans F, Säilynoja E, Vallittu PK, Garoushi S. Mechanical properties and fracture behavior of flowable fiber reinforced composite restorations. Dent Mater 2018;34(4):598-606, http://dx.doi.org/10.1016/j.dental.2018.01.002.

[56] Lassila L, Säilynoja E, Prinssi R, Vallittu P, Garoushi S. Bilayered composite restoration: the effect of layer thickness on fracture behavior. Biomater Investig Dent 2020, in press.

[57] Garoushi S, Lassila LV, Tezvergil A, Vallittu PK. Static and fatigue compression test for particulate filler composite resin with fiber-reinforced composite substructure. Dent Mater 2007;23(1):17-23, http://dx.doi.org/10.1016/j.dental.2005.11.041.

[58] Omran TA, Garoushi S, Lassila LV, Vallittu PK. Effect of interface surface design on the fracture behavior of bilayered composites. Eur J Oral Sci 2019;127(3):276-84, http://dx.doi.org/10.1111/eos.12617.

[59] Krejci I, Duc O, Dietschi D, de Campos E. Marginal adaptation, retention and fracture resistance of adhesive composite restorations on devital teeth with and without posts. Oper Dent 2003;28(2):127-35.

[60] Fokkinga WA, Le Bell AM, Kreulen CM, Lassila LV, Vallittu PK, Creugers NH. Ex vivo fracture resistance of direct resin composite complete crowns with and without posts on maxillary premolars. Int Endod J 2005;38(4):230-7, http://dx.doi.org/10.1111/j.1365-2591.2005.00941.x.

[61] Siso SH, Hürmüzlü F, Turgut M, Altundaşar E, Serper A, Er K. Fracture resistance of the buccal cusps of root filled maxillary premolar teeth restored with various techniques. Int Endod J 2007;40(3):161-8, http://dx.doi.org/10.1111/j.1365-2591.2007.01192.x.

[62] Nam SH, Chang HS, Min KS, Lee Y, Cho HW, Bae JM. Effect of the number of residual walls on fracture resistances, failure patterns, and photoelasticity of simulated premolars restored with or without fiber-reinforced composite posts. J Endod 2010;36(2):297-301, http://dx.doi.org/10.1016/j.joen.2009.10.010.

[63] Scotti N, Eruli C, Comba A, Paolino DS, Alovisi M, Pasqualini $\mathrm{D}$, et al. Longevity of class 2 direct restorations in root-filled teeth: a retrospective clinical study. J Dent 2015;43(5):499-505, http://dx.doi.org/10.1016/j.jdent.2015.02.006. 
[64] Tezvergil-Mutluay A, Vallittu PK. Effects of fiber-reinforced composite bases on microleakage of composite restorations in proximal locations. Open Dent 2014;8:213-9.

[65] Li X, Pongprueksa P, Van Meerbeek B, De Munck J. Curing profile of bulk-fill resin-based composites. J Dent 2015;43(6):664-72,

http://dx.doi.org/10.1016/j.jdent.2015.01.002.
[66] Lehtinen J, Laurila T, Lassila LVJ, Tuusa S, Kienanen P, Vallittu PK, et al. Optical characterization of

bisphenol-A-glycidyldimethacrylate-triethylene

glycoldimethacryalate monomers and copolymers. Dent Mater 2008;24:1324-8. 